\title{
Profile of mirabegron in the treatment of overactive bladder: place in therapy
}

\section{Ala'a Sharaf \\ Hashim Hashim}

Female and Functional Urology Unit, Bristol Urological Institute, Bristol, UK

\begin{abstract}
Mirabegron is a relatively new drug introduced to treat overactive bladder syndrome. It can be used either on its own or as part of a combination. This drug has been extensively studied, with a good number of Phase II and Phase III trials showing promising outcomes. These studies show that mirabegron is an effective, well-tolerated drug, which could have some adverse effects of concern. In this review, we look at the trials on mirabegron, as well as its pharmacokinetics, mechanism of action, and side effects as documented in the literature.
\end{abstract}

Keywords: mirabegron, overactive bladder disorder, antimuscarinics

\section{Introduction}

Mirabegron is the first of a new class of drugs licensed for the management of overactive bladder syndrome $(\mathrm{OAB})$ in over 30 years. It is a human $\beta 3$-adrenoceptor agonist developed by Astellas Pharma Inc. for the treatment of OAB.

$\mathrm{OAB}$ is defined as urinary urgency, usually with urinary frequency and nocturia, with or without urgency urinary incontinence, in the absence of any other pathology. ${ }^{1}$

OAB occurs in both men and women and it has a significant impact on the quality of life. Treatment focuses on lifestyle modification initially, such as weight loss, fluid management, avoiding or reducing caffeine, alcohol, and other bladder irritants, and bladder training. If this fails, antimuscarinics are the first-line treatment option.

Mirabegron has been gaining popularity in the last few years for treating patients with $\mathrm{OAB}$ as an alternative to antimuscarinics.

It was licensed for the treatment of $\mathrm{OAB}$ and has been approved for use in Japan in 2011 (Betanis), USA and Canada in 2012 (Myrbetriq), and Europe in 2013 (Betmiga).

This article will look at mirabegron in the literature and review its pharmacokinetics, adverse effects, and effectiveness in treating OAB.

\section{Pharmacokinetics and mechanism of action}

Detrusor relaxation is mainly mediated by the cyclic adenosine monophosphate pathway. Mirabegron is a potent and selective $\beta 3$-adrenoceptor agonist. It causes increased cyclic adenosine monophosphate concentrations in the rat bladder tissue and shows a bladder relaxant effect. ${ }^{2,3}$ It also results in relaxation of bladder smooth muscle in rat and human isolated tissue.

The chemical name of mirabegron is 2-(2-amino-1,3-thiazol-4-yl)- $N-[4-(2-\{[(2 R)-$ 2-hydroxy-2-phenylethyl]amino \}ethyl)phenyl]acetamide and the chemical formula is $\mathrm{C}_{21} \mathrm{H}_{24} \mathrm{~N}_{4} \mathrm{O}_{2} \mathrm{~S}$ (Figure 1).
Correspondence: Ala'a Sharaf

Urodynamics Department, Southmead Hospital, Southmead Road, Bristol

BSIO 5NB, UK

Tel +44 II7 7960456077

Email ajsharaf@yahoo.com 


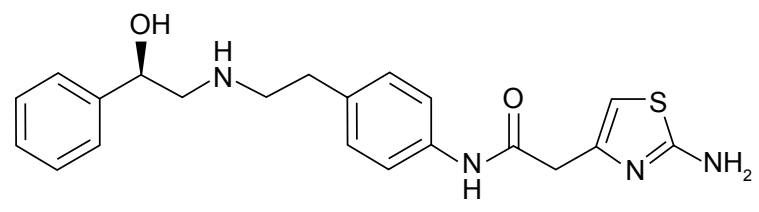

Figure I Chemical structure of mirabegron.

Mirabegron is rapidly absorbed after oral administration, with the time to maximum plasma concentration $\left(\mathrm{T}_{\max }\right)$ being approximately 3 hours and the terminal plasma half-life being 50 hours.

About $70 \%$ of the compound is bound to plasma proteins, mainly to albumin and then to $\alpha 1$-acid glycoprotein. ${ }^{3-5}$

It has an oral bioavailability between $24 \%$ and $53 \%$, which differs with dose and gender. The absolute bioavailability increases from $29 \%$ at a dose of $25 \mathrm{mg}$ to $35 \%$ at a dose of $50 \mathrm{mg}$. Mean maximum plasma concentration $\left(\mathrm{C}_{\max }\right)$ and area under the plasma concentration-time curve (AUC) increased more than dose proportionally over the dose range. ${ }^{3,4}$

The $\mathrm{C}_{\max }$ and $\mathrm{AUC}$ of mirabegron are not affected by the age of the patient. The $\mathrm{C}_{\max }$ and AUC are approximately $40 \%-50 \%$ higher in females than in males. Gender differences in $\mathrm{C}_{\max }$ and AUC are mainly the result of differences in body weight and bioavailability.

Mirabegron is metabolized in the liver mainly by cytochrome P450 (CYP) 3A4, and CYP2D6 plays a minor role in its metabolism. Appropriate monitoring and dose adjustment may be necessary, especially with narrow therapeutic index drugs metabolized by CYP2D6. ${ }^{3,6,7}$

It has a biological half-life of 50 hours, is cleared by multiple mechanisms with no single predominating clearance pathway, and is excreted in both urine (55\%) and feces (34\%). ${ }^{5}$

\section{Mirabegron trials}

The clinical efficacy and safety of mirabegron have been assessed in multiple Phase II and Phase III clinical trials.

This includes the Phase IIa and IIb trials by Chapple et al. In 2013, they reported the results of the BLOSSOM trial. ${ }^{8}$ This was a proof-of-concept, randomized, double-blind, parallel-group, Phase IIa dose-ranging trial with mirabegron in patients with $\mathrm{OAB}$. Tolterodine and placebo were used as controls. Two hundred and sixty patients were enrolled from 31 European sites. The trial showed a statistically significant reduction in the mean micturition frequency from baseline by $17 \%$ with $100 \mathrm{mg}$ and $18 \%$ with $150 \mathrm{mg}$ of mirabegron, when compared with placebo, which resulted in a $9 \%$ reduction, and tolterodine, which resulted in an $11 \%$ reduction. Mirabegron was also significantly superior in reducing the mean volume voided per micturition, mean number of incontinence episodes, nocturia episodes, urgency incontinence episodes, and urgency episodes per 24 hours. $^{3}$

This was followed up in the Dragon trial, which enrolled 919 patients. ${ }^{9}$ The patients were randomized to five groups: placebo, and once-daily mirabegron $25,50,100$, and $200 \mathrm{mg}$ for 12 weeks. This showed statistically significant dosedependent reduction in the mean micturition frequency with 50, 100, and $200 \mathrm{mg}$ of mirabegron, compared with placebo. This trial also showed that mirabegron significantly increased the mean volume voided per micturition, decreased the mean number of incontinence episodes, urgency incontinence episodes, and urgency episodes per 24 hours.

Nitti et al also looked at the urodynamic parameters in men with lower urinary tract symptoms and bladder outflow obstruction treated with mirabegron. ${ }^{10}$ Two hundred male patients were enrolled. Seventy patients received mirabegron $50 \mathrm{mg}, 65$ received mirabegron $100 \mathrm{mg}$, and 65 received placebo. Urodynamic parameters assessed were the change from baseline to the end of treatment in maximum urinary flow rate $\left(\mathrm{Q}_{\max }\right)$ and detrusor pressure at $\mathrm{Q}_{\max }\left(\mathrm{Pdet}_{\mathrm{max}}\right)$. The study showed that mirabegron did not adversely affect the voiding urodynamic parameters such as the bladder contractility index and the bladder voiding efficiency after 12 weeks of treatment, compared with placebo.

Clinical trial evidence for mirabegron is based on four primary Phase III randomized controlled trials (RCTs): Study to Test the Efficacy and Safety of the Beta-3 Agonist Mirabegron (YM178) in Patients With Symptoms of Overactive Bladder (SCORPIO), Study to Test the Efficacy and Safety of the Beta-3 Agonist Mirabegron (YM178) in Patients With Symptoms of Overactive Bladder (ARIES), A Study to Test the Efficacy and Safety of the Beta-3 Agonist Mirabegron (YM178) in Patients With Symptoms of Overactive Bladder (CAPRICORN), and Yamaguchi et al.

ARIES, CAPRICORN, SCORPIO, and the Yamaguchi et al RCTs were all multiple-arm trials in patients with symptoms of OAB. SCORPIO and ARIES evaluated the clinical effectiveness of mirabegron ( 50 and $100 \mathrm{mg}$ ) compared to placebo. CAPRICORN evaluated mirabegron (50 and $25 \mathrm{mg}$ ) against placebo. Yamaguchi et al evaluated the efficacy and safety of mirabegron $50 \mathrm{mg}$ in a Japanese population with $\mathrm{OAB}$ against tolterodine and placebo over 16 weeks.

SCORPIO trial was a multicenter trial conducted by Khullar et al that included Europe and Australia. ${ }^{11}$ It was a randomized, double-blind, parallel-group, placebo- and 
active-controlled Phase III trial in which 1,978 patients were enrolled. All patients had placebo for 2 weeks and then they were randomized. Of them, 493 patients received mirabegron $50 \mathrm{mg}$, 496 received mirabegron $100 \mathrm{mg}$, 495 received tolterodine, and 494 received a placebo for a total of 12 weeks.

The trial showed a statistically significant decrease in the mean number of micturitions from baseline with $50(-1.93)$ and $100 \mathrm{mg}(-1.77)$ of mirabegron and in the mean number of incontinence episodes (-1.57 with $50 \mathrm{mg}$ and -1.46 with $100 \mathrm{mg}$ ) per 24 hours, compared to placebo. A post hoc analysis of the SCORPIO trial showed that both mirabegron doses were effective in improving the coprimary efficacy endpoints versus placebo in antimuscarinic treatment-naïve patients and in patients whose condition failed to respond to previous antimuscarinic therapy, regardless of the reason for discontinuation.

The ARIES trial was a North American, multicenter, randomized, double-blind, parallel-group, placebo-controlled, Phase III trial carried out by Nitti et al. ${ }^{12}$ In this, 1,328 patients were enrolled and randomized to receive either placebo, mirabegron $50 \mathrm{mg}$, or mirabegron $100 \mathrm{mg}$ for 12 weeks. The trial showed a statistically significant reduction in the number of incontinence episodes from baseline with both doses of mirabegron (50 mg [-1.47] and $100 \mathrm{mg}$ [-1.63]), compared to placebo $(-1.13)(P<0.05)$. There was also a significant reduction in the number of micturitions per 24 hours in both mirabegron $50 \mathrm{mg}(-1.66)$ and $100 \mathrm{mg}(-1.75)$ groups, compared to placebo $(-1.05)(P<0.05)$.

The CAPRICORN trial was a Phase III, randomized, double-blind, placebo-controlled trial carried out by Herschorn et al in Europe and North America. ${ }^{13}$ The objective was to assess the efficacy and tolerability of mirabegron 25 and $50 \mathrm{mg}$ once daily versus placebo in patients with OAB. In this trial, 1,306 patients were enrolled and randomized. Of these, 433 received mirabegron $25 \mathrm{mg}$, 440 received mirabegron $50 \mathrm{mg}$, and 433 received placebo for 12 weeks. The primary endpoints were changes in the mean number of incontinence episodes and micturitions per 24 hours at the final visit. Both mirabegron 25 and $50 \mathrm{mg}$ groups showed a reduction in incontinence episodes in 24 hours $(-1.36$ and -1.38 , respectively), when compared to placebo $(-0.96)$ $(P<0.05)$. There was also a reduction in the number of micturition episodes in 24 hours ( -1.65 for mirabegron $25 \mathrm{mg}$ and -1.60 for mirabegron $50 \mathrm{mg}$ ), in comparison to placebo $(-1.18)(P<0.05)$. The results showed that both mirabegron groups demonstrated statistically significant improvements when compared to placebo. However, mirabegron $50 \mathrm{mg}$ showed greater improvement in the mean volume voided per micturition and the mean number of incontinence episodes per 24 hours.

Yamaguchi et al conducted a Phase III RCT evaluating the efficacy and safety of mirabegron $50 \mathrm{mg}$ in a Japanese population with OAB. ${ }^{14}$

A total of 1,139 patients were enrolled and randomized to receive placebo, mirabegron $50 \mathrm{mg}$, or tolterodine $4 \mathrm{mg}$ for 16 weeks. The primary efficacy endpoint was the change in the mean number of micturitions per 24 hours from baseline to final visit.

In this trial, mirabegron $50 \mathrm{mg}$ once daily showed a statistically significant improvement $(P<0.05)$ in the mean number of micturitions per 24 hours $(-1.67 \mathrm{vs}-0.86)$ urgency episodes per 24 hours $(-1.85 \mathrm{vs}-1.37)$, incontinence episodes per 24 hours $(-1.12$ vs -0.66$)$, urgency incontinence episodes per 24 hours $(-1.01$ vs -0.6$)$, and volume voided in each micturition (24.3 vs 9.71), when compared to placebo.

Abrams et al conducted the SYMPHONY trial. ${ }^{15}$ This was a Phase II, factorial design, randomized, double-blind, parallel-group, placebo- and monotherapy-controlled trial conducted at 141 sites in 20 European countries. It included both male and female patients aged 18 years or above with symptoms of $\mathrm{OAB}$ for at least 3 months. In this trial, 1,306 patients were randomized to 12 weeks of treatment in one of 12 groups: six combination groups (solifenacin 2.5, 5, or $10 \mathrm{mg}$ plus mirabegron 25 or $50 \mathrm{mg}$ ), five monotherapy groups (solifenacin $2.5,5$, or $10 \mathrm{mg}$, or mirabegron 25 or $50 \mathrm{mg}$ ), or placebo.

The trial showed that combination therapy with solifenacin and mirabegron significantly improved the mean voided volume, micturition frequency, and urgency, compared with solifenacin $5 \mathrm{mg}$ monotherapy. All combinations were well tolerated, with no important additional safety findings compared with monotherapy or placebo.

Recently, results from the BESIDE study were published. ${ }^{16}$ Macdiarmid et al conducted a randomized, doubleblind, parallel-group, multicenter, Phase IIIb study. A total of 2,174 patients were randomized to a combination of mirabegron $50 \mathrm{mg}$ and solifenacin $5 \mathrm{mg}(\mathrm{n}=727)$, or solifenacin $5 \mathrm{mg}$ $(\mathrm{n}=728)$, or solifenacin $10 \mathrm{mg}(\mathrm{n}=719)$. The study showed that more patients on the combination achieved clinically meaningful improvements in incontinence and micturition frequency. The improvements were accompanied by similar improvements in Patient Perception of Bladder Condition, symptom bother, and health-related quality of life. 


\section{Side effect profile}

Mirabegron does not have the same adverse effects as anticholinergic agents and, thus, may be more tolerable in some individuals who experience side effects with anticholinergics. Mirabegron $50 \mathrm{mg}$ caused dry mouth with an incidence similar to placebo and significantly lower than antimuscarinics.

However, patients who use mirabegron could suffer from side effects such as raised blood pressure, tachycardia, urinary tract infections, constipation, headache, back pain, and dizziness. ${ }^{17}$

Less common side effects include palpitations, atrial fibrillation, urticarial, and joint pain and swelling. ${ }^{12,14,17}$

In 2015, the Medicines and Healthcare Products Regulatory Agency issued a warning stating that mirabegron is contraindicated in patients with severe uncontrolled hypertension, and advice about regular monitoring is being introduced because of cases of severe hypertension. It stated that mirabegron is contraindicated in patients with severe uncontrolled hypertension (systolic blood pressure $\geq 180 \mathrm{mmHg}$ or diastolic blood pressure $\geq 110 \mathrm{mmHg}$, or both). It also recommended that blood pressure should be checked before starting treatment and monitored regularly during treatment, especially in patients with hypertension.

\section{Conclusion}

There are quite a number of RCTs looking at mirabegron, where $>27,000$ patients have been included. ${ }^{18}$ The majority of these trials show that mirabegron $50 \mathrm{mg}$ was efficacious in reducing the frequency of micturition and urgency urinary incontinence episodes, as well as more tolerable in individuals who cannot tolerate antimuscarinics.

Currently, a number of ongoing trials further assess the safety and efficacy of mirabegron in combination with other drugs, such as the PLUS trial which looks at the safety and efficacy of mirabegron when taken with tamsulosin.

\section{Disclosure}

Hashim Hashim is or has been an investigator, lecturer, and consultant for pharmaceutical companies producing or developing drugs for overactive bladder syndrome. The authors report no conflicts of interest in this work.

\section{References}

1. Abrams P, Cardozo L, Fall M, et al. The standardisation of terminology in lower urinary tract function: report from the standardisation subcommittee of the International Continence Society. Urology. 2003;61(1): 37-49.

2. Sacco E, Bientinesi R. Mirabegron: a review of recent data and its prospects in the management of overactive bladder. Ther Adv Urol. 2012; 4(6):315-324.
3. Robinson D, Thiagamoorthy G, Cardozo L. A drug safety evaluation of mirabegron in the management of overactive bladder. Expert Opin Drug Saf. 2016;15(5):689-696.

4. Iitsuka H, Tokuno T, Amada Y, et al. Pharmacokinetics of mirabegron, a $\beta 3$-adrenoceptor agonist for treatment of overactive bladder, in healthy Japanese male subjects: results from single- and multiple-dose studies. Clin Drug Investig. 2013;34(1):27-35.

5. Takusagawa S, van Lier JJ, Suzuki K, et al. Absorption, metabolism and excretion of [14C] mirabegron (YM178), a potent and selective b3-adrenoceptor agonist, after oral administration to healthy male volunteers. Drug Metab Dispos. 2012;40(4):815-824.

6. Rossanese M, Novara G, Challacombe B, Iannetti A, Dasgupta P, Ficarra V. Critical analysis of phase II and III randomised control trials (RCTs) evaluating efficacy and tolerability of a $\beta 3$-adrenoceptor agonist (Mirabegron) for overactive bladder (OAB). BJU Int. 2015;115(1): 32-40.

7. Eltink C, Lee J, Schaddelee M, et al. Single dose pharmacokinetics and absolute bioavailability of mirabegron, a $\beta 3$-adrenoceptor agonist for treatment of overactive bladder. Int J Clin Pharmacol Ther. 2012; 50(11):838-850.

8. Chapple CR, Amarenco G, LópezAramburu MA, et al. A proof-ofconcept study: Mirabegron, a new therapy for overactive bladder. Neurourol Urodyn. 2013;32(8):1116-1122.

9. Chapple CR, Dvorak V, Radziszewski P, et al. A phase II dose-ranging study of mirabegron in patients with overactive bladder. Int Urogynecol J. 2013;24(9):1447-1158.

10. Nitti VW, Rosenberg S, Mitcheson DH, He W, Fakhoury A, Martin NE. Urodynamics and safety of the $\beta 3$-adrenoceptor agonist mirabegron in males with lower urinary tract symptoms and bladder outlet obstruction. J Urol. 2013;190(4):1320-1327.

11. Khullar V, Amarenco G, Angulo JC, et al. Efficacy and tolerability of mirabegron, a $\beta(3)$-adrenoceptor agonist, in patients with overactive bladder: results from a randomised European-Australian phase 3 trial. Eur Urol. 2013;63(2):283-295.

12. Nitti V, Herschorn S, Auerbach S, Ayers M, Lee M, Martin N. The selective [beta] 3-adrenoreceptor agonist mirabegron is effective and well tolerated in patients with overactive bladder syndrome. J Urol. 2011; 185:e783-e784.

13. Herschorn S, Barkin J, Castro-Diaz D, et al. A phase III, randomized, double-blind, parallel-group, placebo controlled, multicentre study to assess the efficacy and safety of the beta3 adrenoceptor agonist, mirabegron, in patients with symptoms of overactive bladder. Urology. 2013; 82(2):313-320.

14. Yamaguchi O, Marui E, Kakizaki H, et al. Phase III, randomised, double-blind, placebo-controlled study of the $\beta 3$-adrenoceptor agonist mirabegron, $50 \mathrm{mg}$ once daily, in Japanese patients with overactive bladder. BJU Int. 2014;113(6):951-960.

15. Abrams P, Kelleher C, Staskin D, et al. Combination treatment with mirabegron and solifenacin in patients with overactive bladder: efficacy and safety results from a randomised, double-blind, dose-ranging, phase 2 study (Symphony). Eur Urol. 2015;67(3):577-588.

16. Macdiarmid S, Al-Shukri S, Barkin J, et al. Mirabegron as add-on treatment to solifenacin in patients with incontinent overactive bladder and an inadequate response to solifenacin monotherapy. J Urol. 2016;196(3): 809-818.

17. Chapple C, Kaplan S, Mitcheson D, et al. Randomised, double-blind, active-controlled phase III study to assess 12-month safety and efficacy of mirabegron, a $\beta(3)$-adrenoceptor agonist, in overactive bladder. Eur Urol. 2013;63(2):296-305.

18. Maman K, Aballea S, Nazir J, et al. Comparative efficacy and safety of medical treatments for the management of overactive bladder: a systematic literature review and mixed treatment comparison. Eur Urol. 2014;65(4):755-765. 


\section{Publish your work in this journal}

Drug Design, Development and Therapy is an international, peerreviewed open-access journal that spans the spectrum of drug design and development through to clinical applications. Clinical outcomes, patient safety, and programs for the development and effective, safe, and sustained use of medicines are the features of the journal, which has also been accepted for indexing on PubMed Central. The manuscript management system is completely online and includes a very quick and fair peer-review system, which is all easy to use. Visit http://www.dovepress.com/testimonials.php to read real quotes from published authors.

Submit your manuscript here: http://www.dovepress.com/drug-design-development-and-therapy-journal 